\title{
Synthesis and Characterization of Cobalt Nanoparticles Using Hydrazine and Citric Acid
}

\author{
S. A. Salman, ${ }^{1,2}$ T. Usami, ${ }^{3}$ K. Kuroda, ${ }^{1}$ and M. Okido ${ }^{1}$ \\ ${ }^{1}$ EcoTopia Science Institute, Nagoya University, Furo-cho, Chikusa, Nagoya 464-8603, Japan \\ ${ }^{2}$ Graduate School of Engineering, Al-Azhar University, Nasr City, Cairo 11371, Egypt \\ ${ }^{3}$ Graduate School of Engineering Nagoya University, Furo-cho, Chikusa-ku, Nagoya 464-8603, Japan \\ Correspondence should be addressed to S. A. Salman; sa.salman@yahoo.com
}

Received 20 September 2013; Revised 24 January 2014; Accepted 9 February 2014; Published 13 March 2014

Academic Editor: Sakhrat Khizroev

Copyright (C) 2014 S. A. Salman et al. This is an open access article distributed under the Creative Commons Attribution License, which permits unrestricted use, distribution, and reproduction in any medium, provided the original work is properly cited.

Cobalt nanoparticles were produced by employing the liquid-phase reduction method and hydrazine. The effect of citric acid additives on the formation and growth mechanism of cobalt nanoparticles was investigated using polarization methods. The cobalt nanoparticles produced in $0.2 \mathrm{M}$ cobalt sulfate and $5 \mathrm{M}$ hydrazine at $298 \mathrm{~K}$ had a spherical shape with a diameter of $400 \mathrm{~nm}$. The dendritic nanoparticles formed with the decreasing of hydrazine concentration at $298 \mathrm{~K}$. On the other hand, dendritic large particles are confirmed at $353 \mathrm{~K}$. It was confirmed that the reduction reaction progressed with the addition of citric acid, and a hexagonal close-packed $(\varepsilon \mathrm{Co})$ phase was formed.

\section{Introduction}

Much work is presently being done around the world to develop hydrogen and fuel-cell technologies so that they will be cost-competitive in diverse applications. Platinum works well as a catalyst in hydrogen fuel cells; however, it has at least two drawbacks in that it is expensive and degrades over time. Eliminating the precious metal platinum would solve a significant economic challenge that has thwarted the widespread use of large-scale hydrogen fuel-cell systems. A new catalytic material based on the element cobalt has been proposed as an alternative to platinum in recent years and might allow the manufacturing of cheaper and more durable hydrogen fuel cells. Cobalt is considered to be the first catalyst made from nonprecious metal with properties closely matching with those of platinum [1]. Cobalt serves also as a model system for the macroscopic magnetic response; because the low to moderate crystal anisotropy allows the effects of size, shape, internal crystal structure, and surface anisotropy to be observed in a single system $[2,3]$. The low crystal anisotropy of cobalt also promotes their study as a model system for the effects of size, shape, crystal structure, and surface anisotropy on their macroscopic magnetic response.
A variety of methods for the preparation of magnetic colloid dispersions have been reported. Cobalt is one of the most important ferromagnetic metals due to its three metastable phases with different crystallographic structures, namely, the hexagonal closed packed (hcp) phase, the face-centered cubic (fcc) phase, and the epsilon phase $[4,5]$.

Synthesizing metallic nanoparticles following wet-chemistry routes is a powerful way of obtaining a reproducible macroscopic amount of homogeneous sample [6]. Several wet-chemical methods have been developed to synthesize cobalt crystals with different morphologies, for example, pyrolysis, solvothermal and hydrothermal decomposition, microfluidic synthesis, modified polyol processes, and template-based methods [7-14]. It has been reported that liquid-phase reduction methods are relatively simple and do not require special equipment. Moreover, they are considered to be less expensive and quicker to implement, which are desirable qualities for future attempts of large-scale production [15].

Much attention has been paid to the characteristics of cobalt nanoparticles; however, there has been little research on the growth mechanism of cobalt nanoparticles. 
The shape and size of the nanoparticles influence the physical characterization of these novel materials.

Therefore, the control of shape and size will increase the possibility of commercial widespread of these materials. So, it is very important to study the effect of kinetic parameters, for example, temperature and time to explain the mechanism of the morphology of the particles from the fundamental viewpoint.

In this study, we attempted to synthesize cobalt nanoparticles at room temperature by employing the liquid-phase reduction method and revealing the formation mechanism of particulates and the reaction mechanism of the reducing agent. Hydrazine $\left(\mathrm{N}_{2} \mathrm{H}_{4}\right)$ was used as a reducing agent in a solution containing a cobalt compound and $\mathrm{Co}^{2+}$ to precipitate the cobalt. Citric acid is a unique capping agent to protect and stabilize metal nanoparticles [16, 17]; therefore, the effect of citric acid additives on the shape and size of produced nanoparticles was investigated.

\section{Experimental}

2.1. Anodic Polarization. A $1 \mathrm{~mol} / \mathrm{dm}^{3}$ solution of hydrazine monohydrate $\left(\mathrm{N}_{2} \mathrm{H}_{4} \cdot \mathrm{H}_{2} \mathrm{O} ; 50.06 \mathrm{MW}\right)$ was dissolved in $200 \mathrm{dm}^{3}$ distilled water, and $0.2 \mathrm{M}$ sodium citrate dihydrate $\left(\mathrm{Na}_{3} \mathrm{C}_{6} \mathrm{H}_{5} \mathrm{O}_{7} \cdot 2 \mathrm{H}_{2} \mathrm{O}\right)$ was added to the solution. Solutions of $\mathrm{NaOH}$ and $\mathrm{H}_{2} \mathrm{SO}_{4}$ were used to adjust the $\mathrm{pH}$. After adjusting the $\mathrm{pH}$, dissolved oxygen was removed by bubbling argon through the solution for $30 \mathrm{~min}$. Polarization measurements were made using a three-electrode potentiostat. A Co plate with surface area of $1 \mathrm{~cm}^{2}$, platinum coil $\left(>1 \mathrm{~cm}^{2}\right)$, and $\mathrm{Ag} / \mathrm{AgCl}$ sat. $\mathrm{KCl}$ were used as working, counter and reference electrodes, respectively. A saturated $\mathrm{KCl}$ agar salt bridge was used as the liquid junction between the reference electrode and electrolyte. The mixture was stirred at a constant speed by a magnetic stirrer during the experiment. The cobalt used had a purity of $99.9 \%$. The anodic polarization measurement was made at a potential sweep rate of $1 \mathrm{mVs}^{-1}$.

2.2. Synthesis of Cobalt Nanoparticles. Hydrazine monohydrate and cobalt sulfate heptahydrate $\left(\mathrm{CoSO}_{4} \cdot 7 \mathrm{H}_{2} \mathrm{O}\right)$ were used as raw materials. A $0.4 \mathrm{M}$ solution of sodium citrate dihydrate was added to $20 \mathrm{~mL}$ of $0.2 \mathrm{M}$ aqueous cobalt sulfate solution. The $\mathrm{pH}$ of the solution was adjusted using $\mathrm{NaOH}$ and $\mathrm{M} \mathrm{H}_{2} \mathrm{SO}_{4}$, and the solution was deaerated by bubbling argon through the solution for $30 \mathrm{~min}$. The solution was maintained at a predetermined temperature and allowed to react for 60 to $120 \mathrm{~min}$. After the solution was centrifuged, suspensions were removed and washed several times with distilled water and dried using a vacuum dryer. The shapes of nanoparticles were observed with a scanning electron microscope (SEM). The phase structures were identified employing $\mathrm{X}$-ray diffraction (XRD). The redox potential (mixed potential) at the working electrode was measured throughout the reduction reaction using a potentiostat. A cobalt plate with surface area of $1 \mathrm{~cm}^{2}$ and $\mathrm{Ag} / \mathrm{AgCl}$ sat. $\mathrm{KCl}$ was used as the working and reference electrodes, respectively.

\section{Results and Discussion}

3.1. Reducing Power of Hydrazine. It is more important to measure the oxidation potential of the reducing agent used in the liquid-phase reduction method than the reduction potential of the metal. To measure the reducing power of hydrazine alone, the anodic polarization was carried out at 353 and $298 \mathrm{~K}$ at various solution $\mathrm{pH}$ values, as shown in Figures 1(a) and $1(\mathrm{~b})$. The oxidation potential decreased and became less noble with an increase in $\mathrm{pH}$. The oxidation of hydrazine depends on $\mathrm{pH}$ because the reaction consumes $\mathrm{OH}^{-}$, as shown in oxidation reaction equation:

$$
\mathrm{N}_{2} \mathrm{H}_{4}+4 \mathrm{OH}^{-} \longrightarrow \mathrm{N}_{2}+4 \mathrm{H}_{2} \mathrm{O}+4 e^{-}
$$

At a high concentration of $\mathrm{OH}^{-}$, the oxidation reaction is likely to occur and the potential decreases.

In addition, the current density sharply increased at $\mathrm{pH}$ $\geq 13$ at $298 \mathrm{~K}$ and $\mathrm{pH} \geq 12$ at $353 \mathrm{~K}$. It is known that hydrazine is a highly reactive base and reducing agent; it acts more strongly as a reducing agent at high $\mathrm{pH}$ values.

The polarization curves of a mixed bath of citric acid and hydrazine at 353 and $298 \mathrm{~K}$ are shown in Figures 1(c) and 1(d). The oxidation potential decreased and became less noble with the addition of citric acid, which indicates that the citric acid improved the reducing power of hydrazine.

Figure 2 shows the potential-pH diagram is drawn using the Nernst equation. The figure shows that it is possible to synthesize cobalt particles using hydrazine because the oxidation potential of hydrazine is less noble than the reduction potential of cobalt. Furthermore, the measured oxidation potential of hydrazine is similar to the theoretical values calculated using the Nernst equation.

Mixed potential with Co and Hydrazine is the potential region between Co reduction (theoretical value) and hydrazine oxidation (experimental value). The oxidation potential does not change with addition of citric acid, which indicates that no complex ion was formed as shown in Figure 2.

Consider the following:

$$
\begin{aligned}
\frac{R T}{z F} \ln \frac{a_{\mathrm{ox}}}{a_{\mathrm{red}}} & =\frac{8.314 \times T}{4 \times 96485} \times 2.303 \log \left[\mathrm{H}^{+}\right]^{4} \\
& =-\frac{8.314 \times 2.303 \times T}{96485}(\mathrm{~V}) \mathrm{pH} \\
& =-(0.0591 \mathrm{~V}) \mathrm{pH}(298 \mathrm{~K}) \\
& =-(0.0700 \mathrm{~V}) \mathrm{pH}(353 \mathrm{~K}) .
\end{aligned}
$$

In the equations, $R$ is the gas constant, $T$ the absolute temperature, $z$ the valence of the ion solution, $a$ the activity, and $F$ Faraday's constant.

The potential-pH diagram shows a notable decrease in the potential at both applied temperatures with the addition of citric acid. Therefore, the addition of citric acid in the liquidphase reduction method can improve the reducing power of hydrazine at low and high $\mathrm{pH}$ values. 


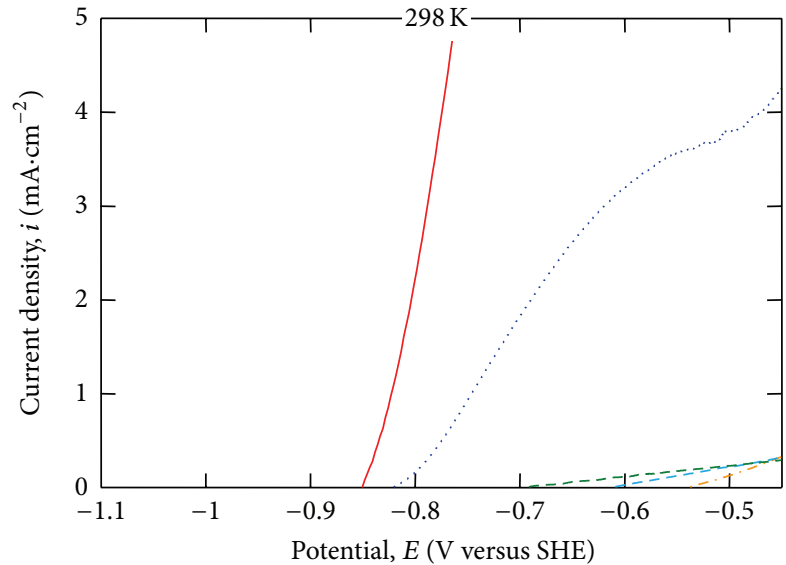

$-\mathrm{pH} 14$ - - - pH 12

$---\mathrm{pH} 11$

-... $\mathrm{pH} 10$

(a)

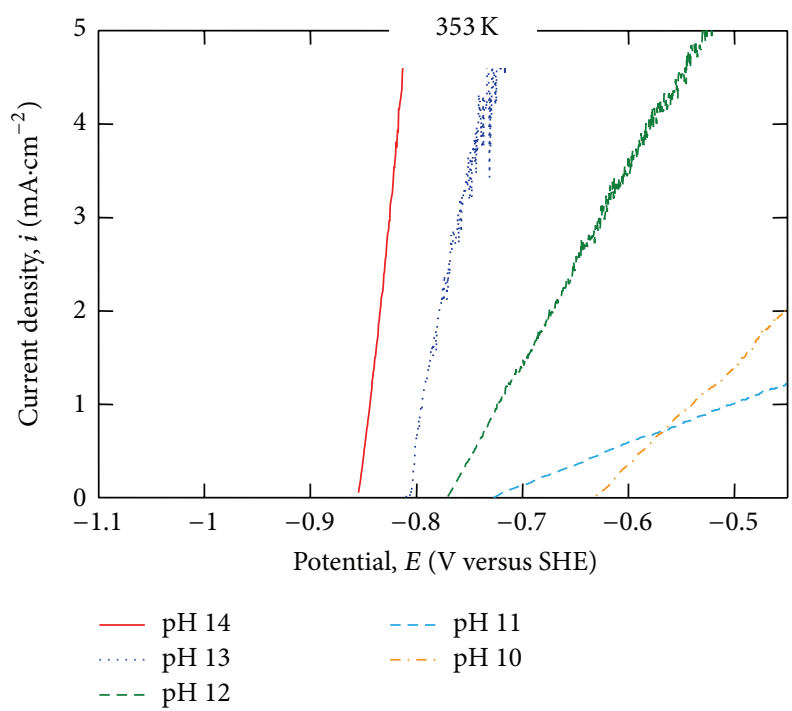

(c)

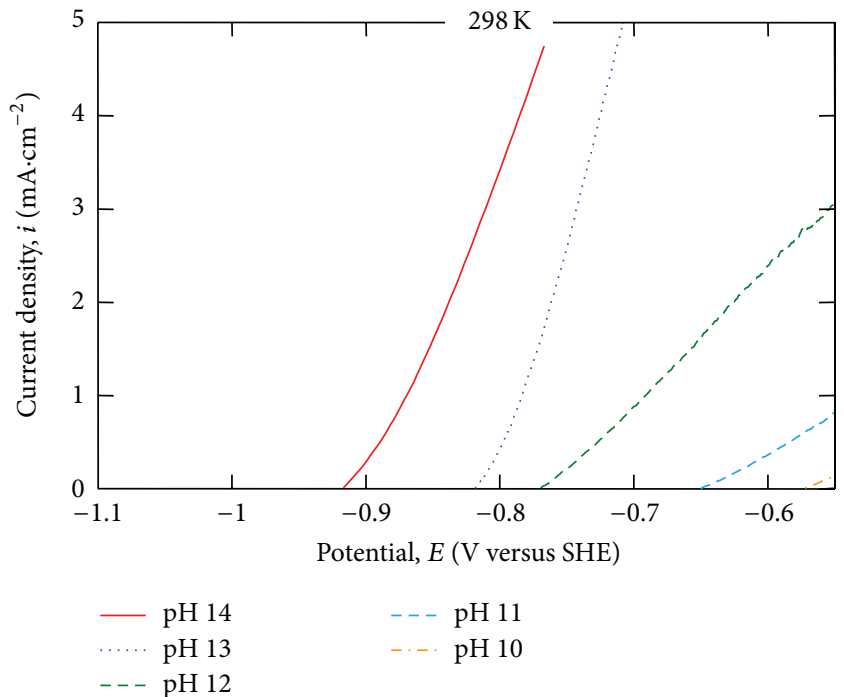

(b)

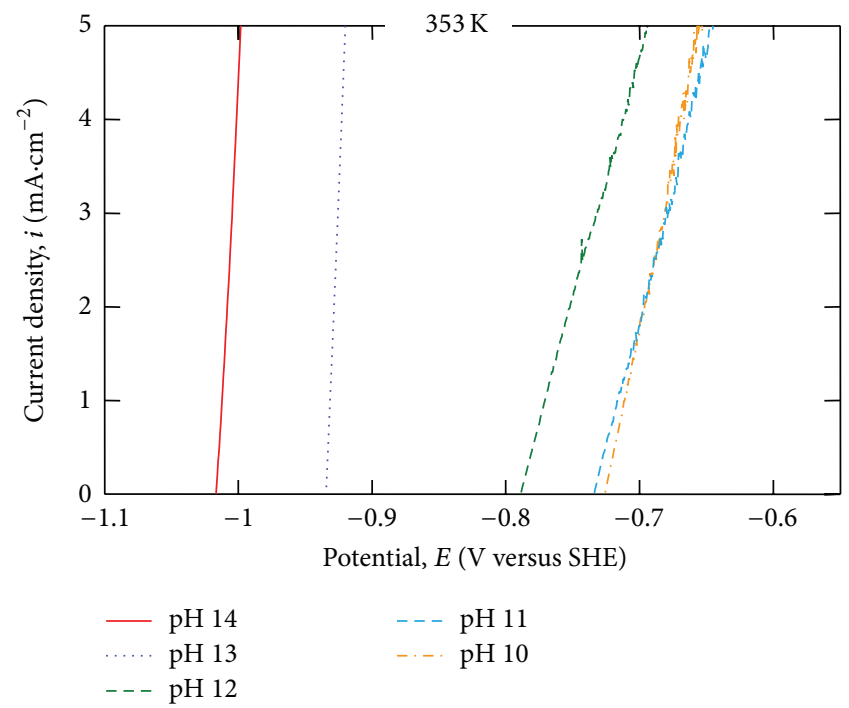

(d)

FIGURE 1: Anodic polarization measurements of hydrazine (a, b) and hydrazine + citric acid (c, d).

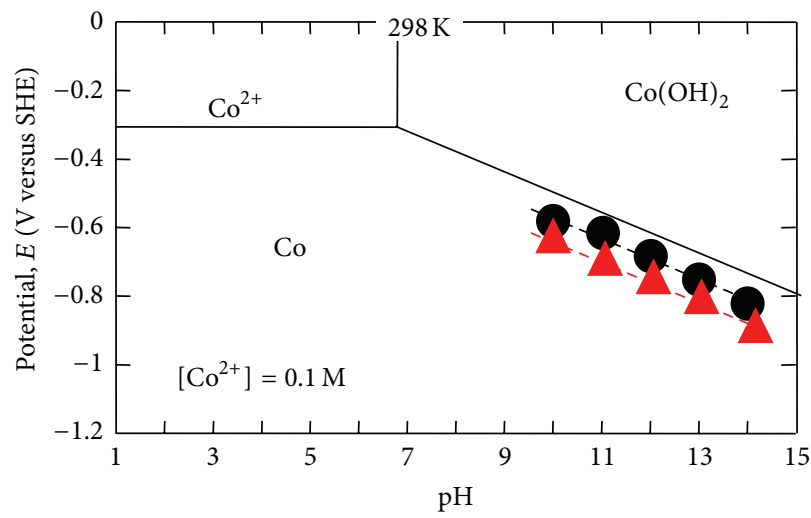

(a)

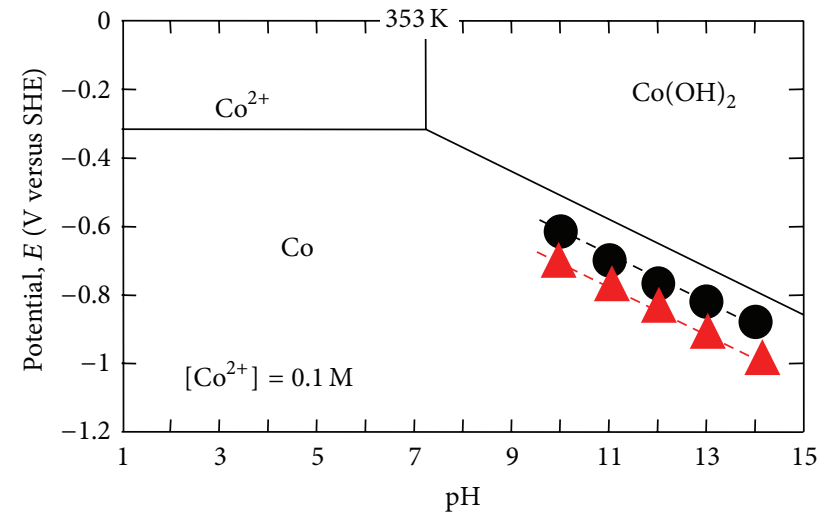

(b)

FIGURE 2: Oxidation potential of hydrazine in a potential-pH diagram of the $\mathrm{Co}-\mathrm{H}_{2} \mathrm{O}$ system. 


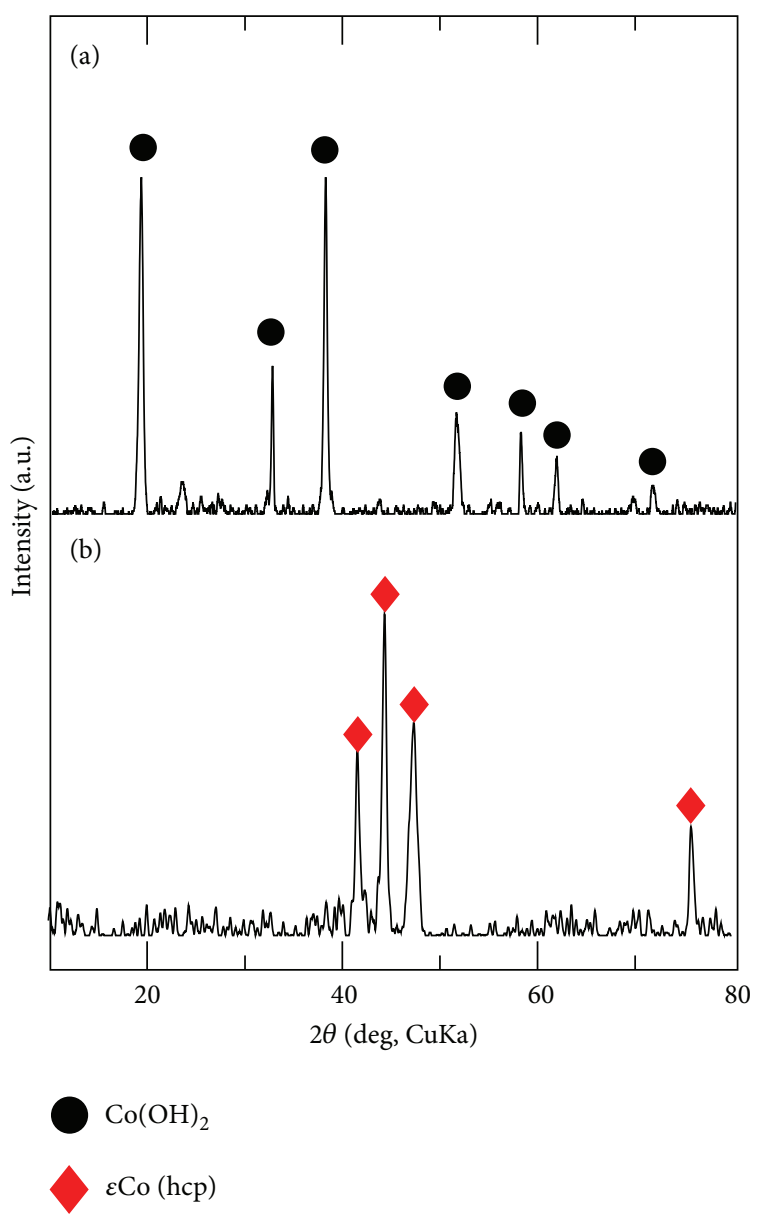

FIGURE 3: XRD patterns of cobalt nanoparticles after 60 min reaction in a solution containing $5 \mathrm{M}$ hydrazine without citric acid (a) and with citric acid (b).

Higher reducing power was observed at a high $\mathrm{pH}$ value of 14; therefore, the $\mathrm{pH}$ of the solution used in the following nanoparticle synthesis experiments was set to 14 .

3.2. Effect of Citric Acid Additives. The effect of adding citric acid on the phase structure is shown in Figure 3. The XRD results show the phase structure of the produced cobalt nanoparticles after $60 \mathrm{~min}$ reaction in a solution containing $5 \mathrm{M}$ hydrazine at a temperature of $298 \mathrm{~K}$. When hydrazine alone was used, several peaks of $\mathrm{Co}(\mathrm{OH})_{2}$ were detected, as shown in Figure 3(a). The reduction reaction progressed by adding the citric acid and a hexagonal close-packed ( $\varepsilon \mathrm{Co})$ phase was formed, as shown in Figure 3(b).

3.3. Cathode Polarization Measurement. A cathodic polarization measurement was carried out to evaluate the role of citric acid.

Figure 4 shows that the cathode current density increased with the addition of citric acid, indicating a high reduction reaction rate. Therefore, the addition of citric acid can effectively improve the reducing power and reaction speed.

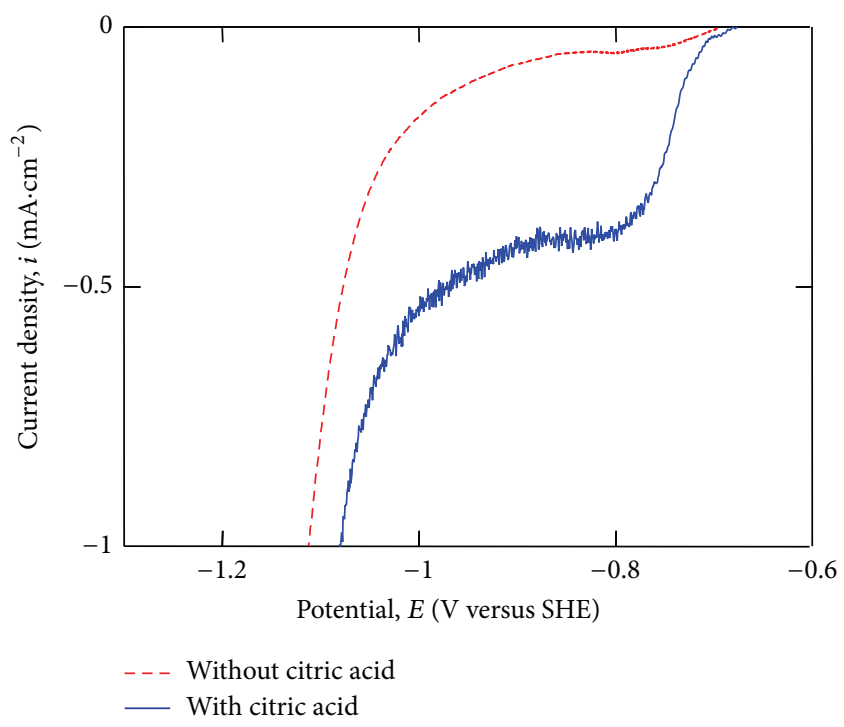

FIGURE 4: Cathodic polarization measurements of hydrazine with and without citric acid at $298 \mathrm{~K}$.

The reduction of cobalt in the liquid-phase reduction method is thought to proceed according to

$$
\begin{gathered}
\mathrm{Co}(\mathrm{OH})_{2} \longrightarrow \mathrm{Co}^{2+}+2 \mathrm{OH}^{-} \\
\mathrm{Co}^{2+}+\mathrm{C}_{6} \mathrm{H}_{5} \mathrm{O}_{7}^{3-} \longrightarrow \mathrm{Co}\left(\mathrm{C}_{6} \mathrm{H}_{5} \mathrm{O}_{7}\right)^{-} \\
2 \mathrm{Co}(\mathrm{OH})_{2}+\mathrm{N}_{2} \mathrm{H}_{4} \longrightarrow 2 \mathrm{Co}+\mathrm{N}_{2}+4 \mathrm{H}_{2} \mathrm{O}
\end{gathered}
$$

The dissociation of $\mathrm{Co}(\mathrm{OH})_{2}$ to $\mathrm{Co}^{2+}$, which is considered the starting point of the reduction reaction, is affected by the speed of the reduction reaction.

SEM images of the nanoparticles produced at 298 and $353 \mathrm{~K}$ for various hydrazine concentrations are shown in Figure 5. The reaction time was set to $120 \mathrm{~min}$ for $2 \mathrm{M}$ hydrazine, $90 \mathrm{~min}$ for $3 \mathrm{M}$ hydrazine, and $60 \mathrm{~min}$ for $5 \mathrm{M}$ hydrazine. Figure 5(a) shows that the cobalt nanoparticles produced in $5 \mathrm{M}$ hydrazine at $298 \mathrm{~K}$ have a spherical shape with a diameter of $400 \mathrm{~nm}$. As the concentration of hydrazine decreases, it is confirmed that dendritic nanoparticles form, and the crystal grows in one direction. This hydrazine diffusion is low at low temperature and the nucleation that takes fast and small particles was formed. At $353 \mathrm{~K}$, dendritic large particles are confirmed, as shown in Figures 5(d), 5(e), and 5(f); the diffusion is of relatively high rate. So, the crystals grew in two directions at high rate even when the hydrazine concentration was $5 \mathrm{M}$.

\section{Conclusions}

We investigated the Synthesis and formation mechanism of cobalt particles in the liquid-phase reduction method. Hydrazine was found to have the reducing power required for the reduction of cobalt. Furthermore, the addition of citric acid improved the reducing power of hydrazine. The addition 


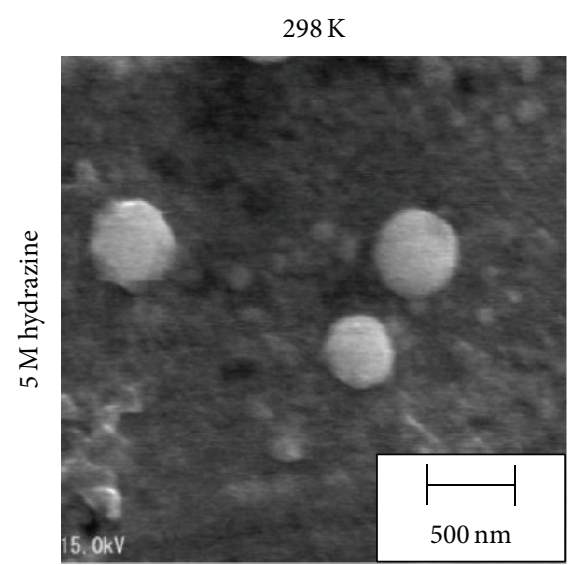

(a)

$298 \mathrm{~K}$

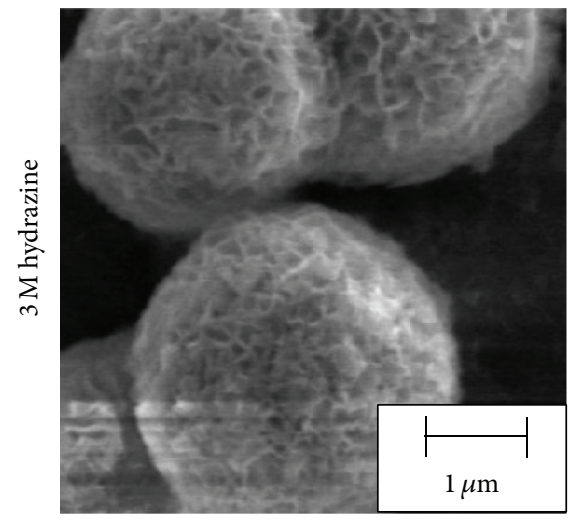

(b)

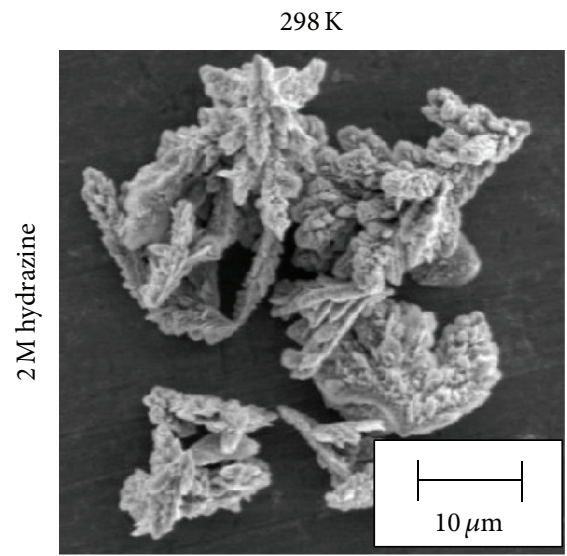

(c)

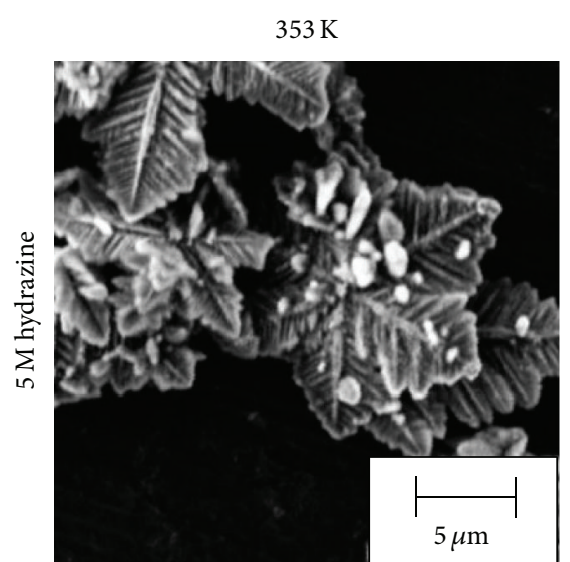

(d)

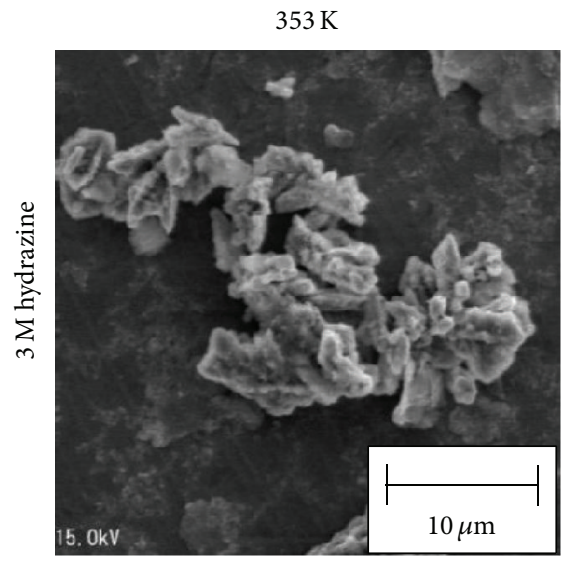

(e)

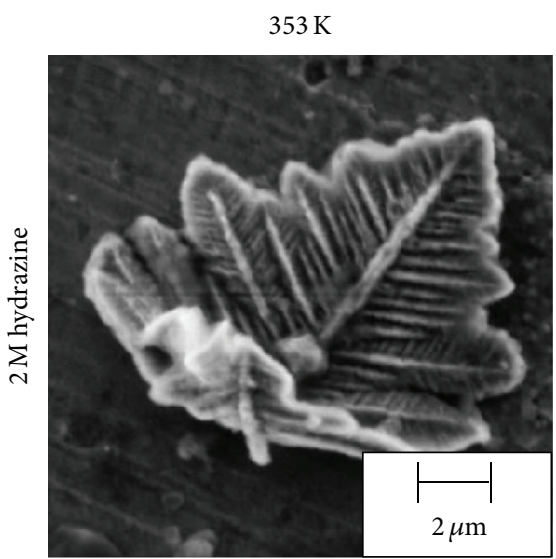

(f)

FIGURE 5: SEM images of cobalt nanoparticles produced at 298 and $353 \mathrm{~K}$ at various hydrazine concentrations.

of citric acid improved the rate of the reduction reaction, and the cobalt nanoparticles produced in $5 \mathrm{M}$ hydrazine had a spherical shape with a diameter of $400 \mathrm{~nm}$. As the concentration of hydrazine decreased, dendritic nanoparticles formed at $298 \mathrm{~K}$. On the other hand, dendritic large particles are confirmed at $353 \mathrm{~K}$. It was confirmed that the reduction reaction progressed by adding citric acid, and a hexagonal close-packed $(\varepsilon \mathrm{Co})$ phase was formed.

\section{Conflict of Interests}

The authors declare that there is no conflict of interests.

\section{Acknowledgments}

The authors gratefully acknowledge the Aichi Center for Industry and Science Technology, the Ministry of Education, 
Culture, Sports, Science and Technology, Japan, and the Ministry of Higher Education, Egypt.

\section{References}

[1] Y. Yu, A. Mendoza-Garcia, B. Ning, and S. Sun, "Cobaltsubstituted magnetite nanoparticles and their assembly into ferrimagnetic nanoparticle arrays," Advanced Materials, vol. 25, no. 22, pp. 3090-3094, 2013.

[2] V. F. Puntes, K. M. Krishnan, and A. P. Alivisatos, "Colloidal nanocrystal shape and size control: the case of cobalt," Science, vol. 291, no. 5511, pp. 2115-2117, 2001.

[3] V. Skumryev, S. Stoyanov, Y. Zhang, G. Hadjipanayis, D. Givord, and J. Nogués, "Beating the superparamagnetic limit with exchange bias," Nature, vol. 423, no. 6942, pp. 850-853, 2003.

[4] B. K. Pandey, A. K. Shahi, R. K. Swarnkar, and R. Gopal, "Magnetic property of novel cobalt sulfate nanoparticles synthesized by pulsed laser ablation," Science of Advanced Materials, vol. 4, no. 3-4, pp. 537-543, 2012.

[5] A.-H. Lu, E. L. Salabas, and F. Schüth, "Magnetic nanoparticles: synthesis, protection, functionalization, and application," Angewandte Chemie International Edition, vol. 46, no. 8, pp. 12221244, 2007.

[6] V. F. Puntes, K. Krishnan, and A. P. Alivisatosa, "Synthesis of colloidal cobalt nanoparticles with controlled size and shapes," Topics in Catalysis, vol. 19, no. 2, pp. 145-148, 2002.

[7] L. Guo, F. Liang, X. G. Wen et al., "Uniform magnetic chains of hollow cobalt mesospheres from one-pot synthesis and their assembly in solution," Advanced Functional Materials, vol. 17, no. 3, pp. 425-430, 2007.

[8] S.-H. Liu, H. Gao, E. Ye et al., "Graphitically encapsulated cobalt nanocrystal assemblies," Chemical Communications, vol. 46, no. 26, pp. 4749-4751, 2010.

[9] X. Wang, F. Yuan, P. Hu, L. Yu, and L. Bai, "Self-assembled growth of hollow spheres with octahedron-like Co nanocrystals via one-pot solution fabrication," The Journal of Physical Chemistry C, vol. 112, no. 24, pp. 8773-8778, 2008.

[10] F. Cao, R. Deng, J. Tang, S. Song, Y. Lei, and H. Zhang, "Cobalt and nickel with various morphologies: mineralizer-assisted synthesis, formation mechanism, and magnetic properties," CrystEngComm, vol. 13, no. 1, pp. 223-229, 2011.

[11] Y. Song, H. Modrow, L. L. Henry et al., "Microfluidic synthesis of cobalt nanoparticles," Chemistry of Materials, vol. 18, no. 12, pp. 2817-2827, 2006.

[12] A. Dakhlaoui, L. S. Smiri, G. Babadjian, F. Schoenstein, P. Molinié, and N. Jouini, "Controlled elaboration and magnetic properties of submicrometric cobalt fibers," Journal of Physical Chemistry C, vol. 112, no. 37, pp. 14348-14354, 2008.

[13] D. D. Li, R. S. Thompson, G. Bergmann, and J. G. Lu, “Templatebased synthesis and magnetic properties of cobalt nanotube arrays," Advanced Materials, vol. 20, no. 23, pp. 4575-4578, 2008.

[14] A.-H. Lu, E. L. Salabas, and F. Schüth, "Magnetic nanoparticles: synthesis, protection, functionalization, and application," Angewandte Chemie International Edition, vol. 46, no. 8, pp. 12221244, 2007.

[15] Z. G. Wu, M. Munoz, and O. Montero, "The synthesis of nickel nanoparticles by hydrazine reduction," Advanced Powder Technology, no. 212, pp. 165-168, 2010.

[16] K. A. Barnes, A. Karim, J. F. Douglas, A. I. Nakatani, H. Gruell, and E. J. Amis, "Suppression of dewetting in nanoparticle-filled polymer films," Macromolecules, vol. 33, no. 11, pp. 4177-4185, 2000.

[17] B. J. Kim, J. Bang, C. J. Hawker, and E. J. Kramer, "Effect of areal chain density on the location of polymer-modified gold nanoparticles in a block copolymer template," Macromolecules, vol. 39, no. 12, pp. 4108-4114, 2006. 

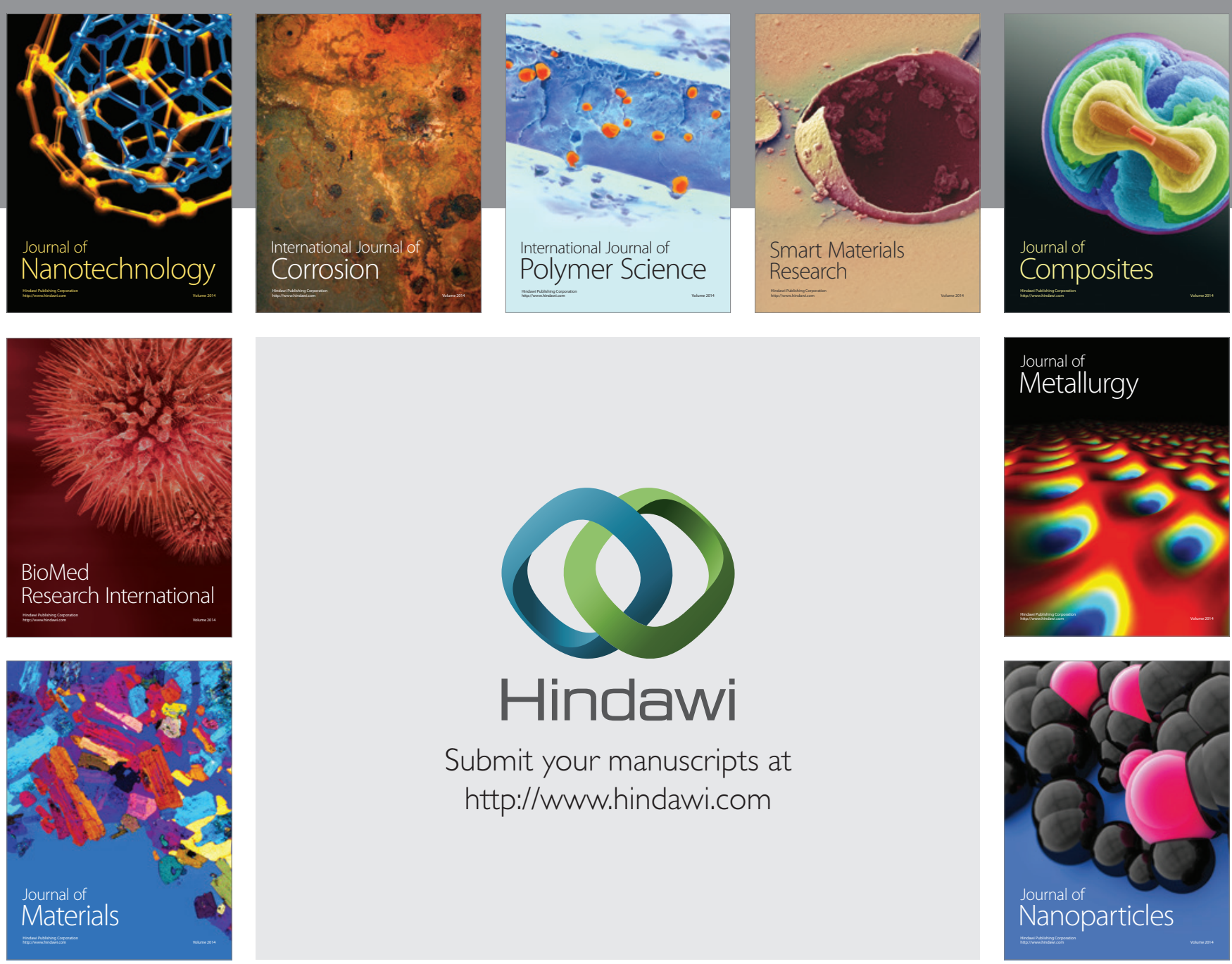

Submit your manuscripts at http://www.hindawi.com
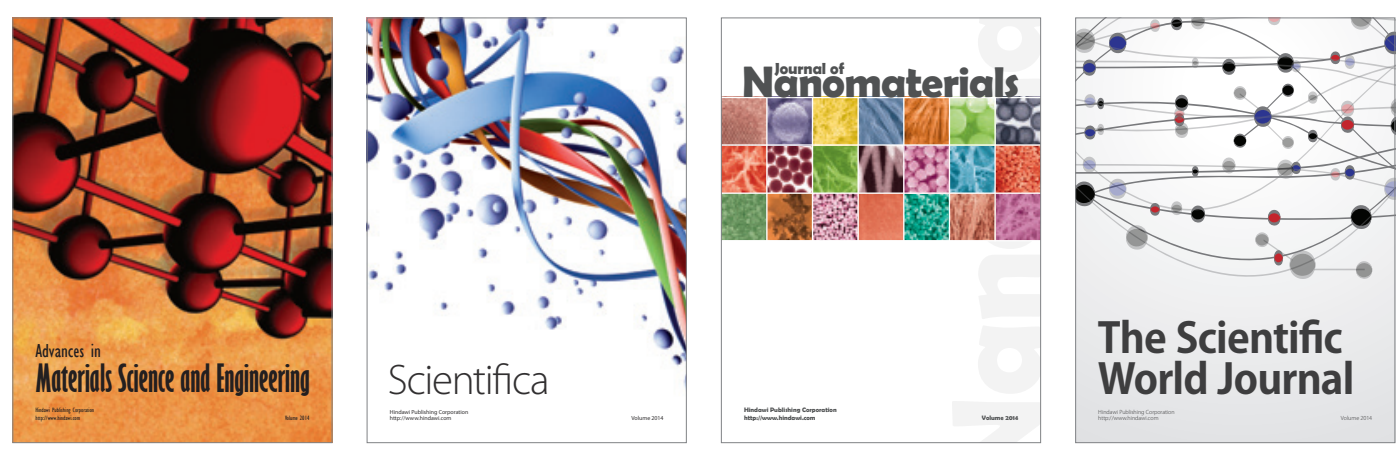

\section{The Scientific World Journal}
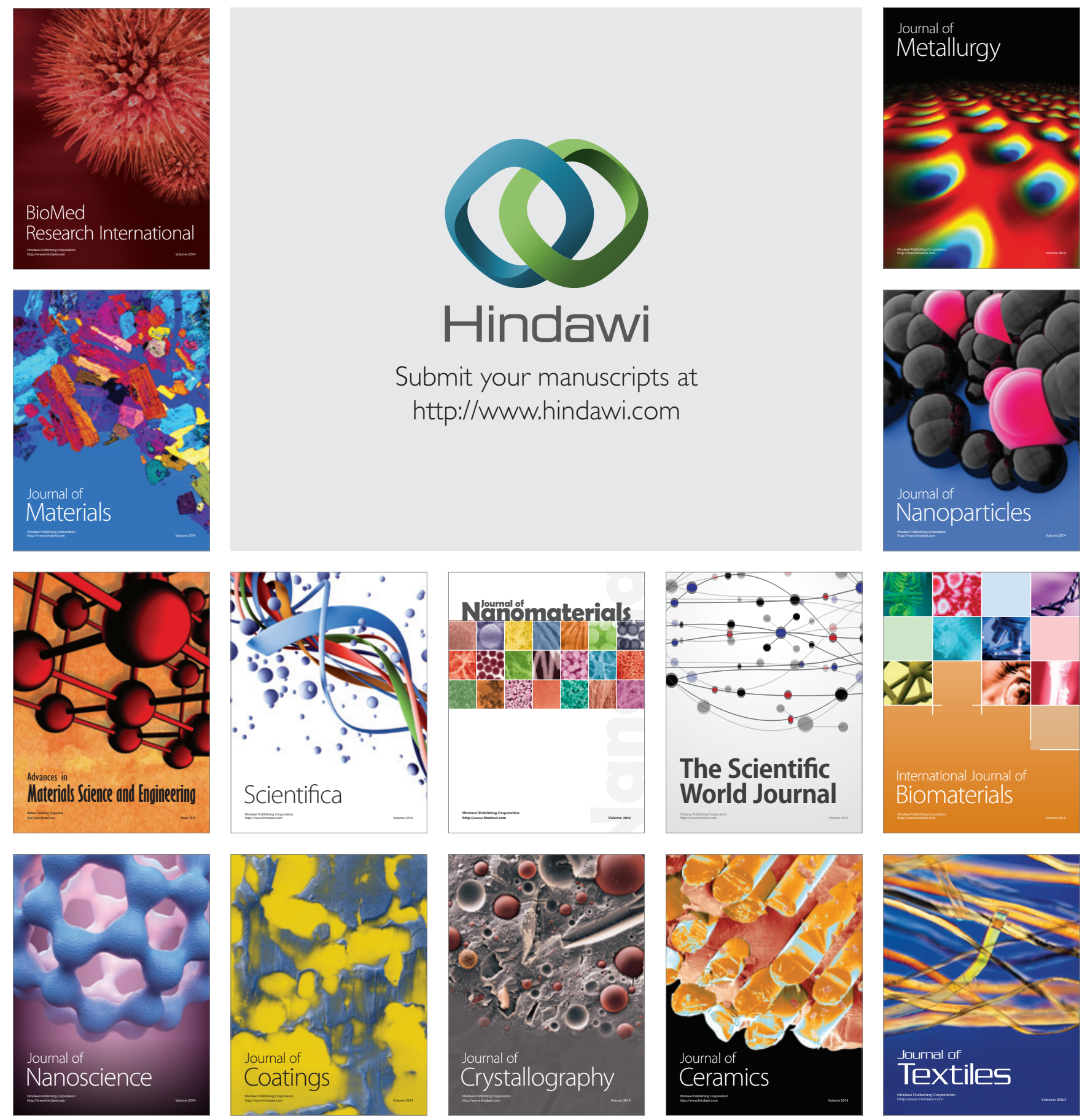